\title{
Accuracy of Computed Tomography Pretreatment Staging and Post-treatment Recurrence in Head and Neck Cancers in Rural Western India- A Retrospective Observational Study
}

\section{ABSTRACT}

Introduction: Cancers of head and neck are the most common in developing countries especially, in India. Multi-disciplinary approach and treatment are required in management of head and neck cancers which include surgeries, radiotherapy techniques and chemotherapy regimens. These can complicate the posttreatment imaging field and contribute to difficulties in image interpretation. Knowledge of these expected post-treatment changes, possible complications and the capability to identify early changes of tumour recurrence is an integral part of posttreatment surveillance and effective management.

Aim: To evaluate the effectiveness of Multi-Detector Computed Tomography (MDCT) in pretreatment staging, post-treatment response and recurrence in comparison with Positron EmissionComputed Tomography (PET-CT).

Materials and Methods: A retrospective observational study was conducted including 101 patients, undergoing pre- and post-treatment, contrast enhanced CT scan with sections from skull base to base of neck. The pretreatment imaging of primary tumour was assessed for its Tumour $(\mathrm{T})$ and Node $(\mathrm{N})$ stage with corresponding staging on histopathology. The imaging observations on pre- and post-treatment scans, for outcomes on recurrence, residual disease and cure were considered. Recurrence when suspected on post-treatment CT scan was confirmed with PET-CT or biopsy. The agreement of $\mathrm{T}$ and $\mathrm{N}$ staging on pretreatment CT scan with that on histopathology was examined using quadratic weighted kappa. Sensitivity and specificity for detection of post-treatment recurrence on CT scan was determined by measuring true positive rates and true negative rates.

Results: An agreement of 0.4 and 0.58 (kappa coefficient) was found between $\mathrm{T}$ and $\mathrm{N}$ staging on $\mathrm{CT}$ and histopathology which suggests fair accuracy of CT in pretreatment staging of head and neck cancers. The CT had a sensitivity and specificity of $88.89 \%$ and $100 \%$ for detecting recurrence in head and neck cancers in post-treatment neck CT scan in the background of post-treatment imaging changes.

Conclusion: The MDCT is a good imaging tool in pretreatment staging of head and neck cancers. It effectively detects recurrence in the background of post-treatment changes. A standard posttreatment evaluation protocol should be followed.

\section{INTRODUCTION}

Cancers of head and neck are the most common cancers in developing countries [1]. The highest rates have been reported from India, Sri Lanka, Pakistan, Bangladesh, Hungary and France [2]. In India, they are most common in men than women [3]. The high incidence of these cancers in India has been attributed to various factors, like use of smokeless tobacco, areca nut, low socio-economic status, poor hygiene, poor diet and viral infections [4-6]. Multi-disciplinary approach and treatment planning are required in management of head and neck cancers which include various surgical approaches of resection, neck dissection and tissue reconstruction along with different radiotherapy techniques as well as concurrent and neoadjuvant chemotherapy regimens. All of these can further complicate the post-treatment imaging field and contribute to difficulties in image interpretation. Knowledge of these expected post-treatment changes, possible complications and the capability to identify early changes of tumour recurrence are an integral part of post-treatment surveillance and effective management [7]. The importance of detection of recurrence lies in its association with high mortality and salvage rate is not more than $36 \%$. Moreover, the prognosis as well as median overall survival after failure of first-line treatment is less than one year [8-11].

Imaging modalities like CT, PET and Magnetic Resonance Imaging (MRI) are considered as valuable modalities for initial staging as well as for post-treatment evaluation of head and neck cancers [12] While Contrast Enhanced Computerised Tomography (CECT) is still considered as the first line investigation available in post-treatment surveillance of patients with head and neck cancers, PET-CT has its evolving role in being more accurate as compared to CT or PET alone in post-treatment response assessment [13,14]. Even though PET-CT fusion has more promising role in post-treatment response assessment, its limited availability and cost burden makes it a complimentary investigation in doubtful cases [15].

Use of MDCT gives the advantage of rapid image acquisition for evaluation of gingiva-buccal and RMT cancers. High spatial resolution of $\mathrm{CT}$ can provide precise anatomic detail.

Combined imaging with PET and CT has been found to be a highly sensitive technique for detection of recurrence of head and neck cancers, post-treatment. However, when PET scan is used in less than 10-12 weeks after completion of radiation therapy, a high false-positive rate occurs because of the presence of postirradiation inflammation, edema or anatomic distortion [16,17]. The CT component of most current CT-PET systems do not have the capabilities of a dedicated CT and therefore have limited image quality [18]. MR provides superior soft-tissue contrast. Diffusion-weighted MR imaging is useful to differentiate tumour recurrence from normal post-treatment changes in the early period after treatment. CT has high sensitivity (63-100\%) for differentiating recurrent tumour from 
post-treatment changes, with increased accuracy in patients treated with non-surgical organ preservation treatment [12,19-27].

Aim of this study was to evaluate effectiveness of MDCT in pretreatment staging, characteristics of post-treatment changes, complications as well as sensitivity and specificity in detection of recurrence, which would allow effective post-treatment surveillance.

\section{MATERIALS AND METHODS}

This was a retrospective observational study including 101 patients with head and neck cancers undergoing pre- and post-treatment, contrast enhanced CT scan with sections from skull base to base of neck, conducted over a period of three years with mean follow-up period of 11.85 months. The study was approved by Institutional Ethics Committee of $\mathrm{HM}$ Patel Centre for Medical Care and Education (IEC/HMPCMCE/87/Faculty/15/37/18).

Inclusion and Exclusion criteria: Patients of either sex with biopsy proven diagnosis of head and neck cancer involving oral cavity, oropharynx and hypopharynx, who underwent pretreatment and post-treatment CT scans, were included in the study. Patients whose pre- and post-treatment CT scans were not available, they were not included in the study.

\section{Study Procedure}

The seventh edition of AJCC cancer staging manual was followed for $\mathrm{T}$ and $\mathrm{N}$ staging [28]. From the pretreatment imaging scans, tumour characteristics for size (greatest dimension), enhancement pattern with presence or absence of necrosis were recorded and the corresponding T staging on histopathology was also noted. The pretreatment nodal status on CECT was also evaluated for size, nodal necrosis, shape of lymph node (round if longitudinal/short axis $<2$, and oval if longitudinal/short axis $>2$ ), margin of lymph node (smooth or ill-defined/irregular), conglomeration of lymph nodes and Perinodal Extension (PNE). A lymph node was considered positive for metastasis if short axis in jugulodigastric nodes was greater than equal to15 $\mathrm{mm}$, retropharyngeal nodes if greater than equal to $8 \mathrm{~mm}$ and the rest of cervical nodes if greater than equal to $10 \mathrm{~mm}$, presence of necrosis, ill-defined irregular margin, and PNE irrespective of the size. The corresponding $\mathrm{N}$ staging and presence of PNE on histopathology were also noted.

The treatment plan was recorded including the status of surgery, radiation therapy and chemotherapy. The type of surgery whether wide excision or composite resection, type of neck dissection whether modified radical neck dissection, radical neck dissection or selective neck dissection and flap reconstruction were recorded.

The imaging observations of treatment outcome on the post-treatment scans were considered for the last available scan at the end of one year post-treatment. The outcome on post-treatment CECT such as presence of recurrence, presence of residual disease and cure were noted. Recurrence was defined as slightly expansible, infiltrative heterogeneously enhancing soft tissue lesion in head or neck with or without bony/cartilage erosion and with or without necrosis $[7,29]$.

Residual disease was defined as persistence of primary lesion observed on pretreatment scan on post-treatment scan [30]. Cure was defined as absence of abnormal soft tissue lesion in head and neck.

Benign post-treatment changes were noted when present. Postradiation complications and postsurgical complications were looked for in the post-treatment CT scan. Recurrence when present on post-treatment CT scan was confirmed with PET-CT or biopsy when available. Details of demography, clinical presentation, tumour site and subsite, observations of pretreatment and post-treatment images were also recorded.

\section{STATISTICAL ANALYSIS}

Stata 14.2 Software was used for statistical analysis. Sensitivity and specificity for detection of post-treatment recurrence as well as PNE on CT scan was determined by measuring true positives rates and true negative rates. Associations between patterns of recurrence and clinical, socio-demographic characteristics, pretreatment imaging features of primary lesion and nodal lesions and posttreatment complications were examined using logistic regression.

\section{RESULTS}

A total of 101 patients with head and neck cancers involving oral cavity, oropharynx and hypopharynx were included. Out of all, $68(67.33 \%)$ had malignancy involving oral cavity, 25 (24.75\%) had malignancy involving oropharynx and only eight (7.92\%) had malignancy involving hypopharynx. Out of the 68 patients with oral cavity cancer, the most common primary subsite was buccal mucosa seen in 66 patients, the rest two had lip and hard palate cancers. There was a preponderance with 82 patients $(81.19 \%)$ being men and mean age at first scan being 52 years [Table/Fig-1]. Tobacco consumption in form of tobacco chewing was associated in 69 (68.32\%) patients with mean duration of 15 years (2.55).

\begin{tabular}{|l|c|c|}
\hline Variables & Category & Frequency (\%) \\
\hline \multirow{2}{*}{ Age (in years) } & Mean (SD) & $52.35(10.91)$ \\
\hline \multirow{2}{*}{ Type of visit } & Female & $19(18.81)$ \\
\cline { 2 - 3 } & Male & $82(81.19)$ \\
\hline \multirow{2}{*}{ Presence of symptoms } & Self-referral & $38(37.62)$ \\
\cline { 2 - 3 } & Follow-up & $63(62.38)$ \\
\hline \multirow{2}{*}{ Tobacco use } & No & $45(44.55)$ \\
\cline { 2 - 3 } & Yes & $56(55.45)$ \\
\hline \multirow{2}{*}{ Duration of tobacco use in years } & No & $32(31.68)$ \\
\hline \multirow{2}{*}{ Primary site of lesion on CT } & Yral cavity & $69(68.32)$ \\
\cline { 2 - 3 } & Oropharynx & $25(24.75)$ \\
\cline { 2 - 3 } & Hypopharynx & $8(7.92)$ \\
\hline \multirow{2}{*}{ [Table/Fig-1]: Demographic and clinical profile. } & \\
\hline
\end{tabular}

Out of 101 patients, 65 (64.35\%) underwent local surgical resection with composite resection in $60(92.30 \%)$, local wide excision in four $(6.15 \%)$ patients and one (1.53\%) patient underwent total laryngectomy with partial pharyngectomy. Out of 101 patients, radical neck dissection was performed in 15 (14.85\%), modified radical neck dissection in 48 (47.52\%), selective neck dissection in one $(0.99 \%)$ and 37 (36.63\%) did not undergo neck dissection [Table/Fig-2]. Out of 65 patients underwent 60 flap reconstruction. Chemotherapy was received by 88 patients and radiation therapy by 76 patients with mean (SD) number of cycles, dose per cycle and cumulative dose of 31 (5.0), 64 (4.4) and 1985.14 (380.0), respectively. The agreement of $\mathrm{T}$ staging and $\mathrm{N}$ staging on pretreatment CT scan with that on histopathology was examined using quadratic weighted kappa with the Cohens kappa coefficient (k) for $\mathrm{T}$ staging on CT compared to $\mathrm{T}$ staging on histopathology being 0.4 therefore level of agreement was fair.

\begin{tabular}{|l|c|c|}
\hline \multirow{2}{*}{ Variable } & Category & $\begin{array}{c}\text { Frequency } \\
\text { (\%) }\end{array}$ \\
\hline \multicolumn{2}{|l|}{ Local excision ( $\mathrm{n=101)}$} & $65(64.35)$ \\
\hline \multirow{3}{*}{$\begin{array}{l}\text { Type of surgical } \\
\text { excision ( } \mathrm{n}=65)\end{array}$} & Wide local excision & $4(6.15)$ \\
\cline { 2 - 3 } & Composite resection & $60(92.30)$ \\
\cline { 2 - 3 } & Total laryngectomy with partial pharyng & $1(1.53)$ \\
\hline \multirow{3}{*}{ Neck dissection ( $\mathrm{n}=101)$} & None & $37(36.63)$ \\
\cline { 2 - 3 } & Radical neck dissection & $15(14.85)$ \\
\cline { 2 - 3 } & Modified radical neck dissection & $48(47.52)$ \\
\cline { 2 - 3 } & Selective neck dissection & $1(0.99)$ \\
\hline
\end{tabular}


We studied frequency distribution of characteristics of pretreatment status of lymphnodes for nodal staging in 95 patients. Broadly on CT scan, 48 (50.52\%) patients had lymphnodes labelled positive for metastasis. Out of all patients, $14.73 \%(n=14)$ showed PNE on CT scan [Table/Fig-3]. Histopathological evidence of PNE status was available in 68 of the 95 patients, which showed that $22.0 \%$ (15 out of 68 patients) had PNE.

\begin{tabular}{|c|c|c|c|}
\hline Variables & $\mathrm{n}$ & Category & Frequency (\%) \\
\hline \multirow{2}{*}{ Size } & \multirow{2}{*}{95} & $<15 \mathrm{~mm}$ & $55(57.89)$ \\
\hline & & $\geq 15 \mathrm{~mm}$ & $40(4.10)$ \\
\hline \multirow{2}{*}{ Shape } & \multirow{2}{*}{95} & $\begin{array}{l}\text { Round-1 } \text { (longitudinal/short } \\
\text { axis }<2 \text { ) }\end{array}$ & $44(46.31)$ \\
\hline & & $\begin{array}{l}\text { Oval-2 (longitudinal/short } \\
\text { axis }>2 \text { ) }\end{array}$ & $51(53.68)$ \\
\hline \multirow{2}{*}{ Margin } & \multirow{2}{*}{95} & Smooth well defined margin & $83(87.36)$ \\
\hline & & III-defined irregular margins & $12(12.37)$ \\
\hline \multirow{2}{*}{ Necrosis } & \multirow{2}{*}{95} & Yes & $32(33.68)$ \\
\hline & & No & $63(66.3)$ \\
\hline \multirow{2}{*}{ Conglomeration } & \multirow{2}{*}{95} & Yes & $7(7.36)$ \\
\hline & & No & $88(92.63)$ \\
\hline \multirow{2}{*}{ PNE on CT } & \multirow{2}{*}{95} & Yes & $14(14.73)$ \\
\hline & & No & $81(85.26)$ \\
\hline \multirow{2}{*}{$\begin{array}{l}\text { Perinodal infiltration on } \\
\text { histopthology }\end{array}$} & \multirow{2}{*}{64} & Yes & $15(22.06)$ \\
\hline & & No & $49(76.56)$ \\
\hline $\begin{array}{l}\text { CECT positivity for } \\
\text { metastasis }\end{array}$ & 95 & Yes & $48(50.52)$ \\
\hline
\end{tabular}

[Table/Fig-3]: Imaging characteristics of lymph nodes on pretreatment CT scan. ${ }^{\star}$ The $\mathrm{N}$ is 95 as rest 6 patients did not have neck lymph nodes

Out of total, 64 patients had both pretreatment CT and histopathological nodal staging available [Table/Fig-4]. The Cohens kappa coefficient $(\mathrm{k})$ for $\mathrm{N}$ staging on CT compared to $\mathrm{N}$ staging on histology was 0.58 , therefore level of agreement was fair.

\begin{tabular}{|c|c|c|c|c|c|c|c|}
\hline \multirow[b]{2}{*}{$\mathrm{N}$ staging on $\mathrm{CT}$} & \multicolumn{6}{|c|}{$\mathrm{N}$ staging on histology } & \multirow[b]{2}{*}{ Total on C1 } \\
\hline & No & N1 & N2A & N2B & $\mathrm{N} 2 \mathrm{C}$ & N3B & \\
\hline No & 33 & 2 & 0 & 0 & 0 & 1 & 36 \\
\hline N1 & 2 & 5 & 1 & 3 & 4 & 3 & 18 \\
\hline N2A & 0 & 1 & 0 & 0 & 1 & 0 & 2 \\
\hline N2B & 0 & 1 & 0 & 0 & 2 & 3 & 6 \\
\hline N3B & 0 & 0 & 0 & 0 & 0 & 2 & 2 \\
\hline TOTAL & 35 & 9 & 1 & 3 & 7 & 9 & 64 \\
\hline
\end{tabular}

We could follow-up 100 patients, one was lost to follow-up. Out of 34 (34\%) patients were followed upto six months, 46 (46\%) patients were followed upto 12 months, 12 (12\%) patients could be followed upto two years and eight (8\%) could be followed for $>2$ years.

On CT evaluation after treatment we found that out of 100 patients, $34(34 \%)$ did not show evidence of recurrence or residual disease, 19 (19\%) showed residual disease and 47 (47\%) showed recurrence. Out of 47 patients who developed recurrence, 40 (85.10\%) could be labelled to have recurrence without any dilemma and seven (14.89\%) patients were labelled to have recurrence with dilemma. Out of these 36 (78\%) patients developed in recurrence within one year. Moreover, out of 47 patients with recurrence 34 (72.36\%) patients developed necrosis within the recurrent lesion and 25 (53.19\%) patients developed bony erosion within recurrent lesion.

We also evaluated post-treatment changes that may or may not have contributed to dilemma in labelling recurrence. Out of 100 patients, 78 patients did not develop any post-treatment change. Thickening of platysma was present in three patients. Changes at post-operative site such as soft tissue fullness [Table/Fig-5] was present in seven patients, cortical erosion was present in one patient, mucosal irregularity was seen in one patient and edema was present in two patients. Soft tissue fullness contributed to dilemma in all seven patients who were doubtful candidates for labelling recurrent lesion. None of our patients developed any post-irradiation complication. Out of 65 patients who underwent local excision, oro-cutaneous fistula developed in three (4.61\%) patients, serous retention cyst [Table/Fig-6] developed in two (3.07\%) patients; sinus developed in two $(3.07 \%)$ patients and oro-antral with oro-cutaneous fistula developed in one (1.53\%) patient.

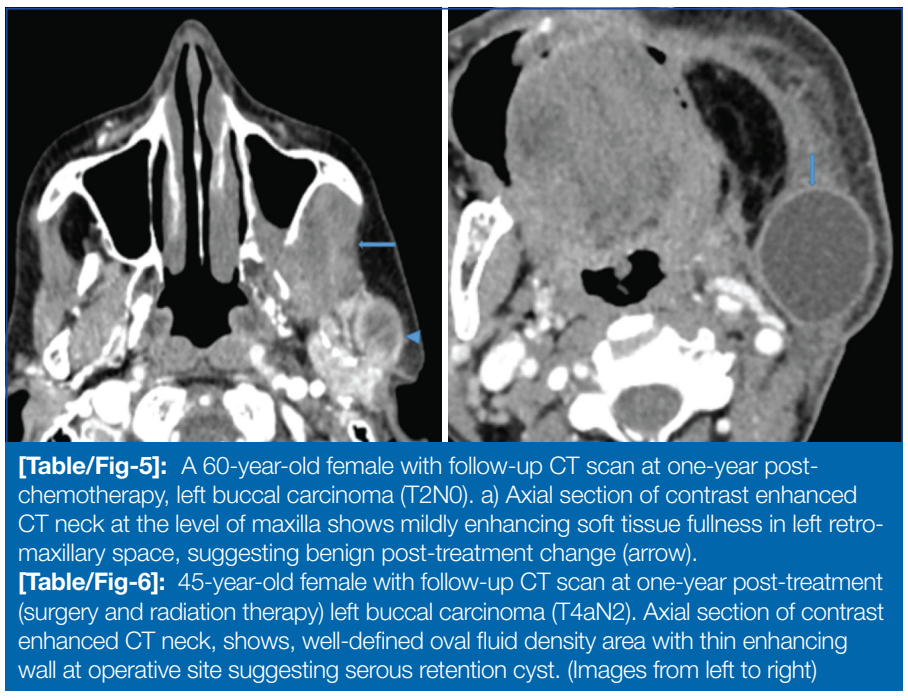

We had 68 patients in whom PET-CT and biopsy both were available to confirm the presence or absence of recurrence post-treatment. In 47 patients who were labelled to have recurrence on post-treatment $\mathrm{CT}$, recurrence was confirmed in all using either PET-CT and biopsy. Based on site of recurrence we observed local recurrence in 37 (78.72\%) [Table/Fig-7,8], whereas local with nodal in one $(2.1 \%)$ and nodal recurrence alone [Table/Fig-9] in seven (14.89\%) and regional in one (2.1\%) [Table/Fig-10]. One patient (2.1\%) presented with distant metastasis.
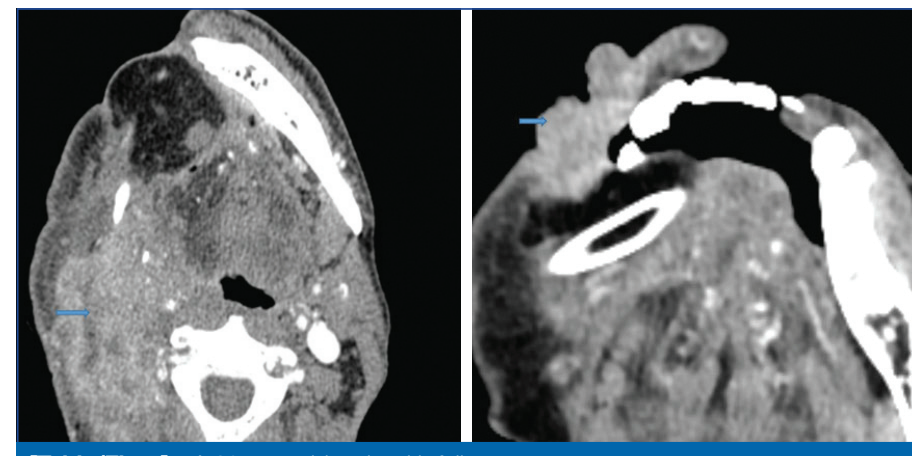

[Table/Fig-7]: A 68-year-old male with follow-up scan at one-year post-treatment (surgery and radiation therapy) right buccal carcinoma (T4aN1). An ill-defined

heterogeneously enhancing area with hypodense areas is noted at flap site, suggesting local recurrence; [Table/Fig-8]: A 55-year-old male with follow-up scan at one-year post-treatment (surgery and radiation therapy) right buccal carcinoma (T4N1). a) Axial section of contrast enhanced CT neck, shows irregular, enhancing, soft tissue lesion at right angle of mouth, suggesting local recurrence. (Images from left to right)

A total of 28 patients were declared disease free on post-treatment CT evaluation and it was observed that 23 patients were confirmed to be disease free using PET-CT or biopsy; however, five patients showed presence of recurrence contradictory to our CT findings. The sensitivity and specificity of determining presence of recurrence on post-treatment CT scan was observed to be $88.89 \%$ and $100 \%$, respectively [Table/Fig-11].

Logistic regression revealed the size of largest lymph node when greater than $15.0 \mathrm{~mm}$ was significantly associated with recurrence \{OR:15.62 with 95\% Cl $(1.58,154.27)$, p-value=0.01\}. No other pretreatment nodal characteristics (conglomeration, necrosis, shape and PNE) as well as lesion characteristics (Retromolar trigone involvement, necrosis in primary lesion, supranotch/infranotch disease and bony erosion) showed any significant correlation with recurrence. 


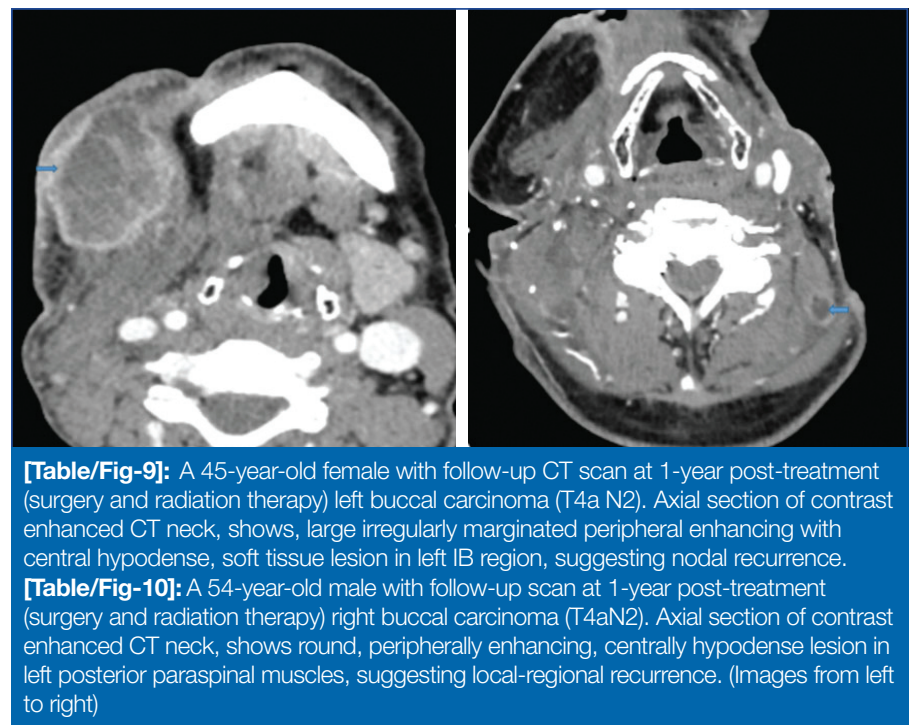

\begin{tabular}{|l|c|c|c|}
\hline \multirow{2}{*}{ Recurrence } & \multicolumn{2}{|c|}{ PET CT or biopsy } & \multirow{2}{*}{} \\
\cline { 2 - 3 } & $+\mathrm{VE}$ & $-\mathrm{VE}$ & Total \\
\hline Recurrence & $40(88.89)$ & 0 & 40 \\
\hline No recurrence & $5(11.11)$ & $23(100)$ & 28 \\
\hline Total & 45 & 23 & 68 \\
\hline
\end{tabular}

[Table/Fig-11]: Sensitivity and Specificity of CT as compared to PET/CT or Biopsy.

\section{DISCUSSION}

In the present study, the kappa coefficient $(k)$ was found fair enough with value of 0.4 and 0.58 , respectively for $T$ and $\mathrm{N}$ staging derived on CT when compared with histopathology. Therefore, $\mathrm{T}$ and $\mathrm{N}$ staging based on $\mathrm{CT}$ imaging in a radiological report may help in prognostication of disease. Our observations are in line with Dammann $\mathrm{F}$ et al., in his prospective study of 79 patients having primary squamous cell carcinoma of oral cavity and oropharynx staging was performed utilising CT, MRI and FDG PET. They reported that CT was a good imaging tool for staging a primary lesion, with PET beneficial in equivocal cases [19]. However, another study by Veit-Haibach P et al., concluded that combined PET/CT was more accurate in assessing overall TNM stage than CT alone [31].

In our study, though soft tissue spread and bony erosion impacted the treatment planning however did not show any correlation with tumour recurrence. The lymphatic dissemination of SCC is an important prognostic indicator. Several CT characteristics like size, shape of node, presence of necrosis and PNE can suggest presence of metastasis. We observed necrosis and conglomeration to be the most reliable criterion for metastasis which is similar as concluded by Arya S et al., whereas Yousem DM et al., reported more accurate detection of metastasis by CT in presence of central nodal necrosis and extra-capsular spread $[32,33]$. Yamazaki $Y$ et al., studied 1076 lymph nodes with preoperative FDG-PET and CT. FDG-PET detected metastatic lymph nodes $\geq 10 \mathrm{~mm}$ more accurately, and had fewer false-positives than CT [34].

In our study, PNE was identified on CT in 14.73\%, whereas histopathology showed that $22.0 \%$ had PNE thus CT had a sensitivity of $33 \%$ and specificity of $98 \%$ for detecting PNE which is in line with a study performed by Prabhu RS et al., which included 432 patients who underwent neck dissection for head and neck cancer and had sensitivity and specificity of $43 \%$ and $97.7 \%$, respectively on CT [35]. A study performed by Aiken $\mathrm{AH}$ et al., was a blinded inter-observer study which included 111 patients with pre-operative CT imaging, followed by pathological evaluation with criteria including lymph node necrosis, irregular borders/stranding, gross invasion for predicting PNE. The sensitivity and specificity was found to be $68 \%$ and specificity of $88 \%$, respectively by the blinded reviewers as compared to sensitivity and specificity of $46 \%$ and specificity of $95 \%$, respectively in the original reports. A higher sensitivity in this study could be due to higher sensitivity of reviewer and criteria for determining PNE [36].
Post-treatment changes are affected by the treatment method, such as the type of surgery, reconstruction, neck dissection, and radiation therapy.

Tumour recurrence may be hard to identify on clinical examination alone, therefore imaging is essential. Most commonly tumours have been found to recur within the first two years. On CT recurrence may be seen as an infiltrating, slightly hyper-attenuating mass with enhancement, progressively enlarging mass, with or without associated bone destruction [Table/Fig-12a,b] [7].

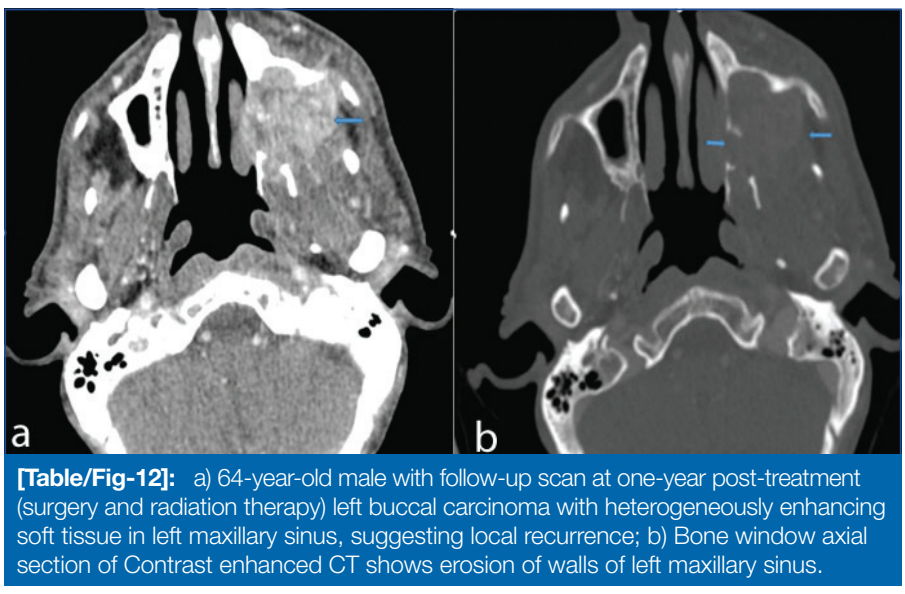

Our study showed a recurrence rate of $47 \%$. Schwartz GJ et al., in their study showed a recurrence rate of $28 \%$ whereas Mucke $T$ et al., in their study showed $23.9 \%[8,10]$. Based on site of recurrence we observed local recurrence in $82.9 \%$ whereas local with nodal in $2.1 \%$ and nodal recurrence alone in $12.7 \%$ and regional in $2.1 \%$.

Our study found CT an effective tool for evaluation of pretreatment and post-treatment status in head and neck cancers with sensitivity and specificity for detection of recurrence being $88.89 \%$ and $100 \%$, respectively, which is comparable to study conducted by Lell $\mathrm{M}$ et al., who studied 331 patients with head and neck cancers who underwent CT after treatment with diagnosis being correlated with histology with sensitivity and specificity being $86 \%$ and $80 \%$, respectively [29]. Bransetter IV BF et al., studied 65 consecutive patients with each patient with PET alone, CT alone and PET/CT combined with a minimum follow-up of six months and biopsy as reference standard. They found that PET/CT was more accurate than PET or CT alone for depiction of malignancy in head and neck with a sensitivity of $98 \%$ and specificity of $92 \%$ [14]. Previous studies have shown the higher accuracy of PET/CT in staging head and neck cancer and in identifying tumour recurrence [16,23-28].

Lowe VJ et al., have demonstrated sensitivities and specificities, respectively, of 38\% and $85 \%$ for conventional imaging and 100\% and $93 \%$ for PET imaging confirming that PET performs significantly better than conventional imaging in detecting recurrent disease [37]. Therefore, although combined PET/CT has a higher sensitivity, CT alone is a good imaging tool with PET/CT reserved for selective cases where is a diagnostic dilemma. Further a baseline CT scan after 3-6 months' therapy would be helpful as it would allow treatment induced changes to be detected and differentiated from recurrence on followup scan. We recommend that a stringent post-treatment evaluation programme to be followed including a base line post-treatment CT scan performed at 3-6 months' postcompletion of therapy. Further, standardisation of post-treatment imaging guidelines could help accurate and early detection of recurrence even before it clinically becomes evident thus allowing timely intervention.

\section{Limitation(s)}

The retrospective nature of this study is associated with several inherent biases. The limitation of our study lies in the duration of follow-up for each patient, a longer duration of follow-up may have 
added further value for predicting disease free survival. Another limitation lies in lack of adherence to a standardised post-treatment imaging protocol the reasons of which may be limited economic resources and patient compliance or early deaths.

\section{CONCLUSION(S)}

Our study concludes that MDCT is a good imaging tool in evaluation of pretreatment as well as post-treatment status in head and neck cancers. Pretreatment $\mathrm{T}$ and $\mathrm{N}$ staging can help to provide a fair judgement of prognosis. MDCT can effectively detect recurrence in the background of complicating post-treatment benign changes and CT alone can be a good tool in post-treatment neck evaluation identifying recurrence and complications with PET/CT reserved for selective cases.

\section{REFERENCES}

[1] WHO 2008. The global burden of disease: 2004 update. ISBN 978924156371 0 (NLM classification: W 74). Available at: www.who.int/evidence/bod.

[2] Ferlay J, Shin HR, Bray F, Forman D, Mathers C, Parkin DM. Estimates of worldwide burden of cancer in 2008: GLOBOCAN 2008. International Journal of Cancer. 2010;127(12):2893-917.

[3] Sankaranarayanan R, Masuyer E, Swaminathan R, Ferlay J, Whelan S. Head and neck cancer: A global perspective on epidemiology and prognosis. Anticancer Res. 1998;18:4779-86.

[4] Mehrotra R, Singh M, Kumar D, Pandey AN, Gupta RK, Sinha US. Age specific incidence rate and pathological spectrum of oral cancer in Allahabad. Indian J Med Sci. 2003;57:400-04

[5] Graham S. Dentition, diet, tobacco and alcohol in the epidemiology of oral cancer. J Natl Cancer Inst. 1977;59:1611-18.

[6] Dayal PK, Mani NJ, Bhargava K. Prevalence of oral cancer and precancerous lesions in 'pan'/'supari' chewers. Indian J Public Health. 1978;22:234-45.

[7] Saito N, Nadgir RN, Nakahira M, Takahashi M, Uchino A, Kimura F, et al. Posttreatment $\mathrm{CT}$ and MR imaging in head and neck cancer: What the radiologist needs to know. Radiographics. 2012;32(5):1261-82.

[8] Schwartz GJ, Mehta RH, Wenig BL, Shaligram C, Portugal LG. Salvage treatment for recurrent squamous cell carcinoma of the oral cavity. Head \& Neck: Journal for the Sciences and Specialties of the Head and Neck. 2000;22(1):34-41.

[9] Matoscevic K, Graf N, Pezier TF, Huber GF. Success of salvage treatment: A critical appraisal of salvage rates for different subsites of HNSCC. Otolaryngology-Head and Neck Surgery. 2014;151(3):454-61

[10] Mücke T, Wagenpfeil S, Kesting MR, Hölzle F, Wolff KD. Recurrence interval affects survival after local relapse of oral cancer. Oral Oncology. 2009;45(8):687-91.

[11] Kostakoglu L, Fardanesh R, Posner M, Som P, Rao S, Park E, et al. Early detection of recurrent disease by FDG-PET/CT leads to management changes in patients with squamous cell cancer of the head and neck. The Oncologist. 2013;18(10):1108.

[12] Mukherji SK, Gapany M, Phillips D, Neelon B, O'O'Brien S, McCartney W, et al. Thallium-201 single-photon emission CT versus CT for the detection of recurrent squamous cell carcinoma of the head and neck. American Journal of Neuroradiology. 1999;20(7):1215-20.

[13] Passero VA, Branstetter BF, Shuai Y, Heron DE, Gibson MK, Lai SY, et al. Response assessment by combined PET-CT scan versus CT scan alone using RECIST in patients with locally advanced head and neck cancer treated with chemoradiotherapy. Annals of Oncology. 2010;21(11):2278-83.

[14] Branstetter IV BF, Blodgett TM, Zimmer LA, Snyderman CH, Johnson JT, Raman $S$, et al. Head and neck malignancy: Is PET/CT more accurate than PET or CT alone? Radiology. 2005;235(2):580-86.

[15] Saif MW, Tzannou I, Makrilia N, Syrigos K. Role and cost effectiveness of PET/ CT in management of patients with cancer. The Yale Journal of Biology and Medicine. 2010;83(2):53.

[16] De Bree R, van der Putten L, Brouwer J, Castelijns JA, Hoekstra OS, Leemans CR. Detection of locoregional recurrent head and neck cancer after (chemo) radiotherapy using modern imaging. Oral Oncol. 2009;45(4-5):386-93.
[17] Subramaniam RM, Truong M, Peller P, Sakai O, Mercier G. Fluorodeoxyglucosepositron-emission tomography imaging of head and neck squamous cell cancer AJNR Am J Neuroradiol. 2010;31(4):598-604.

[18] Makimoto Y, Yamamoto S, Takano H, Motoori K, Ueda T, Kaneoya K, et al. Lymphadenopathy in the mesenteric pedicle of the free jejunal flap: Reactive lymphadenopathy, not metastatic. Journal of Computer Assisted Tomography. 2006;30(1):65-67.

[19] Dammann F, Horger M, Mueller-Berg M, Schlemmer H, Claussen C, Hoffman $\mathrm{J}$, et al. Rational diagnosis of squamous cell carcinoma of the head and neck region: Comparative evaluation of CT, MRI, and 18FDG PET. American Journal of Roentgenology. 2005;184(4):1326-31.

[20] Olmos RA, Balm AJ, Hilgers FJ, Koops W. Thallium-201 SPECT in the diagnosis of head and neck cancer. The Journal of Nuclear Medicine. 1997;38(6):873.

[21] Di Martino E, Nowak B, Hassan HA, Hausmann R, Adam G, Buell U, et al. Diagnosis and staging of head and neck cancer: A comparison of modern imaging modalities (positron emission tomography, computed tomography, color-coded duplex sonography) with panendoscopic and histopathologic findings. Archives of Otolaryngology-Head \& Neck Surgery. 2000;126(12):1457-61.

[22] Kapoor V, Fukui MB, McCook BM. Role of 18FFDG PET/CT in the treatment of head and neck cancers: Posttherapy evaluation and pitfalls. American Journal of Roentgenology. 2005;184(2):589-97.

[23] Anzai Y, Carroll WR, Quint DJ, Bradford CR, Minoshima S, Wolf GT, et al. Recurrence of head and neck cancer after surgery or irradiation: Prospective comparison of 2-deoxy-2-[F-18] fluoro-D-glucose PET and MR imaging diagnoses. Radiology. 1996;200(1):135-41

[24] Greven KM, Williams 3rd DW, Keyes Jr JW, McGuirt WF, Watson Jr NE, Case D. Can positron emission tomography distinguish tumour recurrence from irradiation sequelae in patients treated for larynx cancer?. The cancer journal from Scientific American. 1997;3(6):353.

[25] Lapela M, Grénman R, Kurki T, Joensuu H, Leskinen S, Lindholm P, et al. Head and neck cancer: Detection of recurrence with PET and 2-[F-18] fluoro-2-deoxyD-glucose. Radiology. 1995;197(1):205-11

[26] Rege S, Maass A, Chaiken L, Hoh CK, Choi Y, Lufkin R, et al. Use of positron emission tomography with fluorodeoxyglucose in patients with extracranial head and neck cancers. Cancer. 1994;73(12):3047-58.

[27] Wong WL, Chevretton EB, McGurk M, Hussain K, Davis J, Beaney R, et al. prospective study of PET-FDG imaging for the assessment of head and neck squamous cell carcinoma. Clinical Otolaryngology \& Allied Sciences. 1997;22(3):209-14.

[28] Edge SB, Byrd DR, Compton CC, Fritz AG, Greene FL, Trotti A, editors. AJCC cancer staging manual $\left(7^{\text {th }}\right.$ ed). New York, NY: Springer; 2010.

[29] Lell M, Baum U, Greess H, Nömayr A, Nkenke E, Koester M, et al. Head and neck tumours: Imaging recurrent tumour and post-therapeutic changes with CT and MRI. European Journal of Radiology. 2000;33(3):239-47.

[30] Lee CC, Lee JC, Huang WY, Juan CJ, Jen YM, Lin LF. Image-based diagnosis of residual or recurrent nasopharyngeal carcinoma may be a phantom tumour phenomenon. Medicine. 2021;100(8)

[31] Veit-Haibach P, Luczak C, Wanke I, Fischer M, Egelhof T, Beyer T, et al. TNM staging with FDG-PET/CT in patients with primary head and neck cancer. European Journal of Nuclear Medicine and Molecular Imaging. 2007;34(12):1953-62.

[32] Arya S, Chaukar D, Pai P. Imaging in oral cancers. The Indian Journal of Radiology \& Imaging. 2012;22(3):195.

[33] Yousem DM, Som PM, Hackney DB, Schwaibold F, Hendrix RA. Central nodal necrosis and extracapsular neoplastic spread in cervical lymph nodes: MR imaging versus CT. Radiology. 1992; 182:753-59.

[34] Yamazaki Y, Saitoh M, Notani K, Tei K, Totsuka Y, Takinami S, et al. Assessment of cervical lymph node metastases using FDG-PET in patients with head and neck cancer. Ann Nucl Med. 2008;22:177-84. Doi: 10.1007/s12149-007-0097-9.

[35] Prabhu RS, Magliocca KR, Hanasoge S, Aiken AH, Hudgins PA, Hall WA, et al. Accuracy of computed tomography for predicting pathologic nodal extracapsular extension in patients with head-and-neck cancer undergoing initial surgical resection. International Journal of Radiation Oncology* Biology* Physics. 2014;88(1):122-29.

[36] Aiken AH, Poliashenko S, Beitler JJ, Chen AY, Baugnon KL, Corey AS, et al. Accuracy of preoperative imaging in detecting nodal extracapsular spread in oral cavity squamous cell carcinoma. American Journal of Neuroradiology. 2015;36(9):1776-81.

[37] Lowe VJ, Boyd JH, Dunphy FR, Kim H, Dunleavy T, Collins BT, et al. Surveillance for recurrent head and neck cancer using positron emission tomography. Journal of Clinical Oncology. 2000;18(3):651.

\section{PARTICULARS OF CONTRIBUTORS:}

1. Assistant Professor, Department of Radiodignosis, Shree Krishna Hospital and PS Medical College, Karamsad, Anand, Gujarat, India.

2. Senior Resident, Department of Surgery, Shree Krishna Hospital and PS Medical College, Karamsad, Anand, Gujarat, India.

3. Radiation Oncologist, Department of Oncology, Shree Krishna Hospital and PS Medical College, Karamsad, Anand, Gujarat, India.

4. Professor, Department of Radiodignosis, Shree Krishna Hospital and PS Medical College, Karamsad, Anand, Gujarat, India.

NAME, ADDRESS, E-MAIL ID OF THE CORRESPONDING AUTHOR:

Dr. Radhika Himanshu Pandya,

Assistant Professor, Department of Radiodiagnosis, Shree Krishna Hospital and

Pramukhswami Medical College, Karamsad, Anand-388325, Gujarat, India.

E-mail: itsradhs@gmail.com
PLAGIARISM CHECKING METHODS: [Jain Het al.]

- Plagiarism X-checker: Jul 19, 2021

- Manual Googling: Oct 25, 2021

- iThenticate Software: Nov 13, 2021 (6\%)

\section{AUTHOR DECLARATION:}

- Financial or Other Competing Interests: None

- Was Ethics Committee Approval obtained for this study? Yes

- Was informed consent obtained from the subjects involved in the study? Yes

- For any images presented appropriate consent has been obtained from the subjects. Yes

Date of Submission: Jul 13, 2021 Date of Peer Review: Sep 17, 2021 Date of Acceptance: Oct 27, 2021

Date of Publishing: Jan 01, 2022 